\title{
Crescimento Econômico e Dinâmica Distribucional entre Paíes
}

\author{
Emerson Marinho*, Almir Bittencuort ${ }^{\dagger}$
}

Sumário: 1. Introdução; 2. Metodologia; 3. Dados Amostrais, Estimação e Resultados; 4. Medidas de Produtividade, Relação Capital-Trabalho e Dinâmica Distribucional; 5. Conclusões Finais; A. Cálculo das Variações Médias das Séries de Dados; B. Construção das Medidas.

Palavras-chave: Crescimento econômico, Fronteira estocástica de produção, PTF.

Códigos JEL: C23, 040, 047, 054.

Este artigo examina o desempenho da produtividade agregada de uma amostra de 75 países no período de 1961 a 1990. Com esse objetivo, estimase uma função fronteira estocástica de produção na qual se incorpora efeitos de ineficiência técnica de produção. Em seguida estima-se a produtividade total dos fatores $(P T F)$, através do índice de Malmquist, para decompô-la em variação de eficiência técnica e variação tecnológica. Além da PTF, analisam-se também outras medidas de produtividade e o comportamento da relação capital-trabalho. Entre outros resultados obtidos, encontram-se: a desaceleração da produtividade, o lento crescimento da América Latina, a tendência à bipolarização do padrão de desenvolvimento e a formação de clubes de convergência.

This paper examines the aggregate productivity perfomance to a sample of 75 countries observed over the period 1961-1990. A translog stochastic frontier production function is fitted with inefficiency effects. The Malmquist index is applied and the rate of total productivity of factors growth can be explicitly decomposed into a measure of efficiency change and the rate of technological progress. Results are reported both in form of growth rates and measures of relative productivity levels. In each case related labor productivity measures and capital per worker ratio evolutions are analysed. Among the topics covered are the productivity slowdown, the low growth of Latin America and the bimodality of the distribution of relative productivity levels.

\footnotetext{
* Professor do Curso de Pós-Graduação em Economia - CAEN/UFC. E-mail: emarinho@uf c .br

${ }^{\dagger}$ Professor Pesquisador do Curso de Pós-Graduação em Economia - CAEN/UFC. E-mail: almirbittencourt@uol . com. br
} 


\section{INTRODUÇÃO}

Nos últimos anos, tem-se observado um crescente interesse na quantificação e na comparação do desempenho das nações no que diz respeito à produtividade total dos fatores $(P T F)$.

Uma das implicações desses debates resultou no que passou a ser denominado de hipótese da convergência, segundo a qual os países pobres cresceriam, ao longo do tempo, a taxas mais rápidas que os países ricos, resultando numa tendência de aproximação dos níveis de renda per capita dos primeiros em relação aos últimos.

Os inúmeros trabalhos empíricos realizados acerca de processos de convergência da renda têm permitido demonstrar que para sua efetiva ocorrência duas condições são requeridas: obtenção de níveis similares de intensidade no uso do capital e alcance de padrões tecnológicos equivalentes. Assim sendo, os países pobres teriam que se beneficiar simultaneamente de um maior fluxo de capital fixo e de um processo efetivo de transferência e difusão tecnológica.

O exame empírico da primeira tem sido objeto de maior atenção em face das características de mobilidade internacional do capital e da força da tradição do modelo neoclássico de crescimento (Solow, 1956), que, considera o progresso técnico como exógeno e cuja característica se aproxima de um bem público, estando, portanto, disponível para todas as firmas e países (Mankiw et alii, 1992).

É a partir da publicação dos trabalhos de (Romer, 1986) e Lucas (1988) que se desenvolve uma nova percepção da importância do progresso tecnológico como fonte central do processo de acumulação de capital e do crescimento econômico. Abre-se, assim, uma nova linha de pesquisa e novos estímulos são criados no esforço de modelagem do progresso técnico como elemento central do crescimento de longo prazo.

Em muitos casos, a preocupação com a $P T F$ resulta da arraigada influência de trabalhos empíricos baseados nas abordagens tradicionais da contabilidade do crescimento que a identifica com o progresso técnico. No entanto, deve-se ter muito claro que diferenças existentes nas medidas de PTF entre países não correspondem necessariamente às diferenças nos padrões tecnológicos, uma vez que muitos outros fatores podem explicar essa medida de produtividade além da tecnologia. Por exemplo, variação de eficiência técnica pode afetar a variação da $P T F$. Mas é correto afirmar-se que o progresso técnico conduz a um crescimento da $P T F$, sendo relevante, portanto, o estudo desta última.

O presente artigo vem complementar os estudos realizados pelos autores em outro trabalho (Marinho e Silva, 2003) sobre o comportamento da PTF numa amostra de países da América Latina. Aqui, o objetivo é o de examinar como tem sido o desempenho dessa região relativamente ao de outras regiões (ou grupo econômico de países) no que diz respeito não apenas a essa medida de produtividade, mas também quanto a outros indicadores de performance econômica, inclusive a relação capital-trabalho. Para isso, o trabalho apresenta as medidas da PTF para quatro grupos de países - OCDE (Organização para a Cooperação e o Desenvolvimento Econômico), América Latina, Ásia e África, utilizando-se de dois procedimentos metodológicos: a estimação de uma fronteira estocástica de produção e o cálculo da $P T F$ através do índice de Malmqüist.

Na estimação da fronteira estocástica de produção, incorporam-se efeitos de ineficiência técnica e examina-se simultaneamente a contribuição de variáveis macroeconômicas na explicação do desempenho sobre esta última e sobre a $P T F$ para uma amostra ampla de países. A incorporação de efeitos de ineficiência técnica na função de produção torna o cálculo da $P T F$ dos países mais precisa, pois leva em consideração que alguns deles possam estar abaixo da fronteira de produção, ao contrário dos cálculos realizados pelas abordagens tradicionais em que os países se encontram exatamente sobre a fronteira de produção.

Desde que a $P T F$, calculada pelo índice de Malmqüist, permite sua decomposição em variação de eficiência técnica e variação tecnológica, faz-se uma análise temporal destes componentes. Neste sentido, pode-se analisar para cada um dos países da amostra como a variação de eficiência técnica e a variação tecnológica explicam as variações de suas $P T F$. 
Medidas de produtividade relativa são também construídas seguindo o procedimento adotado por Krüger (2003). Estes autores consideram relevante a comparação das diferenças nos níveis relativos de produtividade entre os países, pois, assim, tem-se uma compreensão mais adequada sobre o comportamento de longo prazo. Essas medidas também serão utilizadas nas estimativas não paramétricas das densidades Kernel, as quais permitem uma melhor visualização da dinâmica da distribuição das variáveis envolvidas ao longo do tempo, conforme o proposto por (Quah, 1996a,b, 1997).

$O$ restante do artigo está estruturado como segue. A seção dois discute a metodologia. A seção três especifica a amostra, descreve os dados e apresenta a estimação do modelo e os resultados dos testes. Na seção quatro, são apresentadas as variações de produtividade obtidas do índice de Malmqüist, as medidas de produtividade relativa e os seus comportamentos dinâmicos são analisados por meio da estimação das densidades Kernel. A última seção é dedicada ao sumário dos resultados e às conclusões.

\section{METODOLOGIA}

\subsection{Fronteira estocástica de produção}

o procedimento adotado para o cálculo da $P T F$ foi o método paramétrico conhecido como fronteira estocástica de produção. Uma de suas principais vantagens em relação aos métodos não paramétricos reside na incorporação, além dos distúrbios aleatórios, de efeitos de ineficiência técnica na estimação da fronteira.

No entanto, ao contrário dos métodos não paramétricos, se faz necessário a especificação de uma forma funcional para a fronteira de produção e o indispensável estabelecimento de hipóteses distribucionais sobre os distúrbios e da ineficiência técnica.

O modelo de fronteira de produção objeto deste trabalho baseia-se na abordagem de dados em painel, desenvolvida por Battese e Coelli (1995), a qual permite que se modele o efeito de ineficiência técnica. Neste sentido, além das variáveis tradicionais como trabalho e capital que explicam o produto, pode-se acrescentar adicionalmente um conjunto de variáveis que expliquem a ineficiência técnica.

Essa modelagem tem a vantagem de permitir que as ineficiências técnicas e as elasticidades dos insumos variem no tempo, possibilitando a identificação de alterações na estrutura de produção.

Assim sendo, o modelo ${ }^{1}$ é definido como segue:

$$
y_{i t}=\beta_{i f}+\beta_{t} t+\beta_{t t} t^{2}+\sum_{j=1}^{2} \beta_{j} x_{j i t}+\sum_{j=1}^{2} \sum_{h=1}^{2} \beta_{j h} x_{j i t} x_{h i t}+\sum_{j=1}^{2} \beta_{j i t} x_{j i t} t+v_{i t}-u_{i t}
$$

em que,

$y_{i t}$ representa o logaritmo do produto observado no tempo, $t$, relativo à i-ésima unidade de produção (país);

$\beta_{\text {if }}$ são os efeitos fixos a serem estimados com a finalidade de capturar heterogeneidades no painel de dados;

\section{$t$ é a variável tempo;}

$x_{j i t}$ representa os logaritmos dos fatores de produção relativo à i-ésima unidade produtiva e medida no tempo $t$. Para $j=K$, este fator de produção é o estoque de capital. Para $j=L$, este fator de produção é o trabalho;

\footnotetext{
${ }^{1}$ A forma funcional da fronteira estocástica foi determinada através de um teste de máxima verossimilhança de adequação à amostra de dados. Testou-se a forma funcional translog, que apresenta propriedades menos restritivas, em contraposição a uma Cobb-Douglas. $O$ resultado do teste apresentado na Tabela 2 concluiu por uma translog.
} 
$\beta=\left(\beta_{t}, \beta_{t t}, \beta_{j}, \beta_{j h}, \beta_{j i t}\right)$ é um vetor de parâmetros desconhecidos a serem estimados onde $j=K, L \mathrm{e}$ $h=K, L$;

$v_{i t}$ representa os erros aleatórios e são, por hipótese, independentes e identicamente distribuídos com distribuição normal, tendo média zero e variância $\sigma_{v}^{2}$, não conhecida;

$u_{i t}$ representa a ineficiência técnica na produção e, por hipótese, é sempre maior ou igual a zero.

Neste caso, o modelo incorpora efeitos fixos com a finalidade de capturar heterogeneidades no painel de dados e a mudança tecnológica especificadas como, $\beta_{t} t+\beta_{t t} t^{2}$, representa a taxa de progresso técnico ou o deslocamento da função de produção ao longo do tempo. Essa especificação considera o progresso técnico como não-neutro. A adoção da hipótese de retornos constantes de escala na função de produção 1, a fim de possibilitar a construção do índice de Malmqüist, implica as seguintes restrições sobre os parâmetros dessa função: $\beta_{K}+\beta_{L}=1, \beta_{K K}+\beta_{K L}=0, \beta_{K L}+\beta_{L L}=0$ e $\beta_{K t}+\beta_{L t}=0$.

Os efeitos de ineficiência técnica, $u_{i t}$, são modelados como:

$$
u_{i t}=\delta z_{i t}+w_{i t}
$$

em que,

$u_{i t}$ é a ineficiência técnica que por hipótese tem distribuição normal truncada em zero, independentemente distribuída (mas não identicamente distribuída) com média, $m_{i t}=E\left(u_{i t}\right)=\delta z_{i t} \mathrm{e}$ variância, $\sigma_{u}^{2}$;

$z_{i t}$ é um vetor de variáveis que explicam a ineficiência técnica $u_{i t}$. Para $i=1, z_{1 t}$, é o gasto com o consumo do governo em relação ao produto interno bruto de cada país. Para $i=2, z_{2 t}$, é o desvio do nível de preços local em relação à paridade do poder de compra (PPP), tomando-se os Estados Unidos da América como país de referência. A sua inclusão tem como objetivo controlar os efeitos das políticas de comércio que implementam desvalorizações no câmbio real sobre a ineficiência técnica. Um crescimento nos desvios dos preços locais em relação à PPP significa desvalorização no câmbio real. Para $i=3, z_{3 t}$, é o grau de abertura, medido pelo valor da soma das importações e exportações em relação ao produto interno bruto de cada país. Espera-se, em geral, que economias mais abertas tenham maior acesso à importação de bens intermediários mais baratos, uma maior penetração a amplos mercados e a tecnologias mais avançadas;

$\delta$ é um vetor de parâmetros desconhecidos a serem estimados;

$w_{i t}$ é uma variável aleatória com distribuição normal de média zero e variância $\sigma_{w}^{2}$;

A estimação simultânea e eficiente dos parâmetros das equações 1 e 2 é operacionalizada pelo método de máxima verossimilhança, cuja função de verossimilhança se encontra em Battese e Coelli (1993). Esta função é parametrizada por $\gamma=\frac{\sigma_{u}^{2}}{\left(\sigma_{u}^{2}+\sigma_{v}^{2}\right)}$ onde, $\sigma_{u}^{2}+\sigma_{v}^{2}$, é a variância total do erro composto de 1. Este procedimento além de facilitar o processo de maximização por iterações, uma vez que o valor do referido parâmetro deve situar-se entre zero e um, permite realizar teste estatístico para verificar a existência de efeitos de ineficiência técnica na função de produção 1. Quanto mais próximo de um for o valor estimado de $\gamma$, maior é a importância da eficiência técnica nos desvios em relação à fronteira de produção.

\subsection{Função distância}

Para se calcular a produtividade total dos fatores, através do índice de Malmqüist, se faz necessário usar o conceito de função distância. Neste sentido, faz-se a seguir uma discussão sobre este conceito. 
O conjunto de possibilidades de produção, $P\left(x^{t}\right)$, para um dado período de tempo $t$, representa o conjunto de todos os vetores de produtos, $y^{t}=v\left(y_{1}^{t}, y_{2}^{t}, \ldots, y_{M}^{t}\right) \in R_{+}^{M}$, que pode ser produzido com o vetor dos insumos, $x^{t}=\left(x_{1}^{t}, x_{2}^{t}, \ldots, x_{N}^{t}\right) \in R_{+}^{N}$. Em outras palavras, é o conjunto de todas as combinações de insumos e produtos factíveis.

A função distância orientada pelo produto ${ }^{2}$ pode ser definida utilizando o conceito do conjunto de possibilidades de produção. Denotando a função distância orientada pelo produto por, $D_{o}^{t}\left(x^{t}, y^{t}\right)$, para um período de tempo $t$, sua definição formal é expressa por:

$$
D_{o}^{t}\left(x^{t}, y^{t}\right)=\operatorname{Inf}\left\{\left(\delta:\left(x^{t}, y^{t} / \delta\right) \in P\left(x^{t}\right)\right\}\right.
$$

Essa função mede a máxima expansão proporcional do produto observado necessária para garantir a igualdade entre ele e o produto potencial máximo, determinado pela fronteira do conjunto de possibilidades de produção $P\left(x^{t}\right)$.

A função distância, $D_{o}^{t}\left(x^{t}, y^{t}\right)$, caracteriza completamente a tecnologia de tal modo que, $D_{o}^{t}\left(x^{t}, y^{t}\right) \leq$ 1 , se e somente se, $D_{o}^{t}\left(x^{t}, y^{t}\right) \in P\left(x^{t}\right)$. Além do mais, $D_{o}^{t}\left(x^{t}, y^{t}\right)=1$, se e somente se a observação situa-se sobre a fronteira de produção, sendo, portanto, eficiente no sentido de Farrell (1957).

De acordo com Farrell (1957), pode-se utilizar o conceito de função distância orientada pelo produto, para um dado conjunto de insumos, como uma medida de eficiência técnica de produção. Esta medida refere-se à distância entre o produto observado e o produto potencial máximo, sendo medida como uma proporção deste último. Dito de outro modo, a função distância é a expansão proporcional máxima do produto de modo a torná-lo eficiente.

\section{3. Índice de produtividade total de Malmqüist}

O índice de Malmqüist (1953) foi proposto inicialmente para analisar questões relacionadas ao consumo e Caves et alii (1982) posteriormente adaptaram-no como um índice de produtividade. $O$ índice de produtividade total de Malmqüist apresenta duas vantagens em relação ao procedimento da contabilidade do crescimento. Em primeiro lugar, não há necessidade de se ter informações sobre os preços de fatores de produção e nenhuma condição de equilíbrio é requerida para sua construção. A outra vantagem é que o referido índice permite decompor a variação na $P T F$ nos componentes de variação de eficiência técnica e de variação tecnológica. Com isso, pode-se identificar qual destas componentes contribui mais para a variação da $P T F$, ao contrário da contabilidade do crescimento que associa alterações na $P T F$ diretamente aos avanços na tecnologia.

Considerando a relevância de se evitar qualquer escolha arbitrária do período de referência, o índice de produtividade total de Malmqüist, aqui denotado por, $P T F M$, é apresentado no formato proposto por Fare et alii (1994), de acordo com a expressão:

$$
\text { PTFM }=\left[\frac{D_{o}^{t+1}\left(y^{t+1}, x^{t+1}\right)}{D_{o}^{t}\left(y^{t}, x^{t}\right)}\right]\left[\frac{D_{o}^{t}\left(y^{t+1}, x^{t+1}\right)}{D_{o}^{t+1}\left(y^{t+1}, x^{t+1}\right)} x \frac{D_{o}^{t}\left(y^{t}, x^{t}\right)}{D_{o}^{t+1}\left(y^{t}, x^{t}\right)}\right]^{\frac{1}{2}}
$$

O primeiro termo do lado direito de (3) mede a variação de eficiência relativa, ou seja, distância do produto observado em relação ao produto potencial máximo entre os períodos $t$ e $t+1$. Este termo quantifica a variação de eficiência técnica $(V E T)$ de produção e é conhecido na literatura como efeito cathing-up. O segundo quantifica o deslocamento da fronteira de produção devido ao progresso técnico entre os períodos $t$ e $t+1$ avaliado em $x^{t}$ e $x^{t+1}$. Este termo representa exatamente a variação tecnológica $(V T)$. Assim sendo, tem-se que:

\footnotetext{
${ }^{2}$ A função distância também pode ser definida orientada pelos insumos. Denotando-a por, $D_{i}\left(x^{t}, y^{t}\right)$, tem-se que $D_{i}\left(x^{t}, y^{t}\right)=$ $\sup \left\{\rho:\left(x^{t} \mid \rho, y^{t}\right) \in L\left(y^{t}\right)\right\}$ onde o conjunto de insumos $L\left(y^{t}\right)$ representa todos os vetores de insumos, $x^{t}$, que podem produzir o vetor de produtos, $y^{t}$. Isto é, $L\left(y^{t}\right)=\left\{x^{t}: x^{t}\right.$ pode produzir $\left.y^{t}\right\}$. Ela mede a máxima contração do vetor de insumos, $x^{t}$, de forma que $y^{t}$ ainda possa ser produzido.
} 


$$
\begin{gathered}
V E T=\left[\frac{D_{o}^{t+1}\left(y^{t+1}, x^{t+1}\right)}{D_{o}^{t}\left(y^{t}, x^{t}\right)}\right] \\
V T=\left[\frac{D_{o}^{t}\left(y^{t+1}, x^{t+1}\right)}{D_{o}^{t+1}\left(y^{t+1}, x^{t+1}\right)} x \frac{D_{o}^{t}\left(y^{t}, x^{t}\right)}{D_{o}^{t+1}\left(y^{t}, x^{t}\right)}\right]
\end{gathered}
$$

Portanto, para se calcular a $P T F M, V E T$ e a, $V T$, precisa-se primeiramente calcular as distâncias $D_{o}^{t}\left(x^{t}, y^{t}\right), D_{o}^{t+1}\left(x^{t+1}, y^{t+1}\right), D_{o}^{t}\left(x^{t+1}, y^{t+1}\right)$ e $D_{o}^{t+1}\left(x^{t}, y^{t}\right)$.

\subsection{Estimações não paramétricas: funções Kernel}

A estimação das densidades Kernel permite identificar a dinâmica de evolução das distribuições da $P T F M, V E T, V T$, produto per capita, produto por trabalhador, e relação capital/trabalho.

A função kernel escolhida foi a de Epanechnikov, em função de dois aspectos: os valores das distribuições das variáveis consideradas na análise inserem-se no seu domínio de definição e a sua eficiência em relação às outras funções Kernel é máxima. Além disso, de acordo com Silverman (1998), esse procedimento permite uma identificação adequada do grau de assimetria e da bimodalidade das distribuições.

Para a estimação do kernel faz-se necessário a determinação do comprimento das faixas do histograma que é denominado de bandwidth. A finalidade do bandwidth é justamente suavizar o histrograma, ou seja, tornando-o uma função densidade contínua.

Na estimação destas densidades, de acordo com (Silverman, 1998), o bandwidth ótimo, $h$, é determinado pela seguinte expressão, $h=\frac{(0,9 \varphi)}{\left(n^{\frac{1}{5}}\right)}$, onde: $\varphi=\min \left[(\text { variância de } x)^{\frac{1}{2}}\right.$, (intervalo interquartil de $\left.\frac{x}{1,349}\right), x$ é a variável para a qual se deseja estimar o kernel e $n$ representa o número de observações.

\section{DADOS AMOSTRAIS, ESTIMAÇÃO E RESULTADOS}

\subsection{Dados amostrais}

Os dados foram extraídos de duas fontes básicas: Penn World Table 6.1 (PWT 6.1), (Heston et alii, 2002) e World Development Indicators (WDI), construído pelo Banco Mundial (BIRD). Esses bancos de dados internacionais são amplamente referenciados em estudos empíricos, notadamente sobre o crescimento econômico de países e regiões, uma vez que as informações disponíveis são sistematizadas de acordo com metodologias que possibilitam cada vez mais comparações reais entre diferentes economias. As fontes dos dados e as variáveis utilizadas são especificadas a seguir. Da PWT6.1 retirou-se as seguintes variáveis: as séries de produto (RGDPCH - Real GDP per capita - Constant price: chain series e RGDPWOK - Real GDP chain per worker), grau de abertura (OPENK - Openness in Constant prices), gastos do governo (Kg - Government share of RGDL - Real GDP per capita - constant price Laspeyres), população (POP), desvio dos preços em relação à PPP (P - Price level of Gross Domestic Product - US = 100), trabalho (obtido por cálculo com o uso das variáveis: RGDPCH, RGDPWOK e POP). Da WDI selecionou-se a série capital (KAPW - Capital per worker).

De acordo com Nuxoll (1994), os dados das séries de produto e dos fatores de produção são utilizados em nível na estimação da fronteira estocástica em vez do procedimento bastante adotado de considerar essas variáveis sob a forma de taxas de variação. Isto se justifica pelo fato de que, o uso de preços internacionais para ajustar as diferenças no poder de compra das moedas de diferentes países, tende a superestimar as taxas de crescimento dos países ricos e a subestimar as dos países mais pobres. Assim, evita-se a introdução de viés nos dados e, em conseqüência, sobre as estimações.

Os modelos especificados neste trabalho são aplicados para uma amostra de dados anuais composta de 75 países no período compreendido entre os anos de 1961 e 1990 . A amostra é constituída de 2.250 observações sob a forma de um painel balanceado. Para minimizar-se a possibilidade de viés de 
seleção, a amostra selecionada decorreu do critério de escolha do maior número possível de países em que houvesse disponibilidade de informações sobre capital físico no tempo mais remoto, em bancos de dados confiáveis. Como muitos países, notadamente os países em desenvolvimento, somente possuem informações sobre capital físico a partir de 1961, este ano passou a definir o limite inferior da série. Da mesma forma, o limite superior ficou definido pelo ano de 1990, porque não há a partir desse ano informações de capital para os países. Evitou-se, portanto, um procedimento bastante usual e de certo modo arbitrário, a construção de séries de estoque de capital utilizando a técnica de inventário.

\subsection{Estimação e resultados}

As estimativas dos parâmetros da fronteira de produção e do componente da ineficiência técnica, equações 1 e 2 , estão, respectivamente, apresentadas na Tabela 1. Todos os parâmetros estimados são estatisticamente significantes no nível de $5 \%$, com exceção do parâmetro da variável tempo ao quadrado que resultou não significante.

O sinal positivo do parâmetro $\beta_{t}$ indica a ocorrência de progresso técnico, embora sua magnitude não tenha sido expressiva. O indicador de ineficiência técnica, $\gamma$, apresenta o valor aproximado de 0,99 , sendo também estatisticamente significante. Esse resultado significa que $99 \%$ da variância total do erro composto da função de produção 1 é explicado pela variância do termo da ineficiência técnica. Isto mostra a importância de incorporar no modelo a ineficiência técnica na função de produção.

Quanto aos parâmetros das variáveis que explicam a ineficiência técnica, todos os parâmetros estimados também se apresentam estatisticamente significantes para o nível de 5\%. Quanto aos sinais esperados, discuti-se a seguir.

O coeficiente relativo à variável gastos correntes do governo $\left(z_{1 t}\right)$ é positivo e significante, sugerindo que elevadas participações desse componente dos gastos na composição do dispêndio agregado dos países introduz ineficiência na economia.

Assim, países com elevados gastos correntes tendem em média a serem menos eficientes. Esse resultado pode ter como explicação o fato de que a pressão por gastos públicos mais elevados resulta em um efeito deslocamento nos investimentos produtivos, gerando distorções na alocação de recursos nas economias.

A variável desvios dos preços locais em relação à PPP $\left(z_{2 t}\right)$ tem coeficiente negativo e significante. Assim, os países que praticaram políticas comerciais baseadas na desvalorização do câmbio real lograram reduzir o seu grau de ineficiência através do mecanismo de preços.

A variável grau de abertura $\left(z_{4 t}\right)$ apresenta coeficiente positivo e significante, indicando, portanto, que economias mais abertas possuem um grau maior de ineficiência técnica. Esse resultado é surpreendente e contraria as previsões de que economias com maior grau de abertura teriam acesso a bens intermediários a preços mais baixos, a tecnologias mais avançadas e a mercados mais amplos, o que lhes permitiria elevar a ineficiência técnica. Pode-se apresentar como uma possível explicação para esse resultado inesperado a heterogeneidade da amostra que inclui países cujas economias são voltadas para a exportação de produtos primários e naturais, de baixo nível de desenvolvimento e com elevada ineficiência sistêmica.

Na Tabela 2, apresentam-se os resultados de alguns testes estatísticos com a finalidade de verificar a consistência de hipóteses específicas relacionadas à função fronteira de produção estimada e aos componentes da ineficiência técnica.

O primeiro teste refere-se ao teste de adequação da forma funcional da função de produção. Testase a hipótese nula de uma função translog, na forma da equação (1), contra uma Cobb-Douglas que apresenta propriedades menos restritivas que esta última. O valor da razão de verossimilhança $(154,1)$ supera o valor crítico da estatística $\chi_{(6)}^{2}$ para o nível de significância de $5 \%$. Com isso, rejeita-se a especificação na forma de uma função Cobb-Douglas em favor do modelo translog.

$O$ segundo teste testa o modelo translog sem os efeitos fixos. Os resultados levam à rejeição desse modelo em favor de se considerar efeitos fixos na fronteira de produção. 
Tabela 1 - Estimativas de máxima-verossimilhança dos parâmetros da fronteira estocástica de produção *

\begin{tabular}{|c|c|c|}
\hline Parâmetros/Variáveis & Estimativa & Valor-t \\
\hline \multicolumn{3}{|c|}{ Fronteira Estocástica de Produção } \\
\hline$t$ & 0,01145 & 6,05 \\
\hline$\left(\frac{1}{2}\right) t^{2}$ & 0,00003 & 0,32 \\
\hline $\ln K$ & $-0,21906$ & $-3,83$ \\
\hline$t \ln K$ & $-0,00127$ & $-5,09$ \\
\hline $\ln L$ & 1,21906 & 21,16 \\
\hline$t \ln L$ & 0,00127 & 4,78 \\
\hline$\left(\frac{1}{2}\right)(\ln K)^{2}$ & 0,08348 & 12,19 \\
\hline $\ln K \ln L$ & $-0,08348$ & $-12,19$ \\
\hline$\left(\frac{1}{2}\right)(\ln K)^{2}$ & 0,08348 & 12,19 \\
\hline \multicolumn{3}{|l|}{ Efeitos de Ineficiência Técnica } \\
\hline$\delta_{0}$ (intercepto) & $-1,21906$ & $-14,03$ \\
\hline$\delta_{1}\left(z_{1}-\right.$ gastos de consumo do governo) & 1,19185 & 13,78 \\
\hline$\delta_{2}\left(z_{2}\right.$ - desvios dos preços locais em relação à PPP) & $-0,31249$ & $-10,09$ \\
\hline \multirow[t]{2}{*}{$\delta_{3}\left(z_{3}-\right.$ grau de abertura $)$} & 0,47901 & 21,76 \\
\hline & Variâncias & $\lambda^{* *}$ \\
\hline$\sigma_{\epsilon}^{2}$ & 0,11558 & \\
\hline$\gamma$ & 0,98804 & 666,26 \\
\hline Eficiência Média & 0,88560 & \\
\hline Log da Função de Verossimilhança & 1906,08 & \\
\hline
\end{tabular}

* Os efeitos fixos dos países não são apresentados na Tabela.

** A distribuição assintótica desse teste de hipótese envolve um parâmetro g que se caracteriza por possuir uma distribuição qui-quadrado mista cujos valores críticos são obtidos na Tabela 1 de Kodde e Palm (1986, p. 1246).

*** Fonte: elaborada pelos autores.

Tabela 2 - Teste da razão de verossimilhança dos parâmetros da fronteira estocástica de produção*

\begin{tabular}{|c|c|c|c|c|c|}
\hline Teste & Hipótese Nula $\left(H_{0}\right)$ & $\begin{array}{l}\text { Log- } \\
\text { Verossimilhança }\end{array}$ & Valor de $\lambda$ & Valor Crítico & $\begin{array}{l}\text { Decisão } \\
\text { (Nível de 5\%) }\end{array}$ \\
\hline 1 & $\begin{array}{l}\beta_{t t}=\beta K t=\beta_{L t}=\beta_{K K}= \\
\beta_{L L}=\beta_{K L}=0\end{array}$ & 1829,28 & 154,10 & 11,91 & Rejeita H0 \\
\hline 2 & $\begin{array}{l}\beta_{1 f}=\beta_{2 f}=\beta_{3 f}=\ldots= \\
\beta_{75 f}=0\end{array}$ & $-223,20$ & 2129,28 & 55,19 & Rejeita H0 \\
\hline 3 & $\beta_{t}=\beta_{t t}=\beta_{L t}=\beta_{K t}=0$ & 1860,22 & 91,72 & 8,76 & Rejeita H0 \\
\hline 4 & $\delta_{0}=\delta_{1}=\delta_{2}=\delta_{3}=0$ & 1700,01 & 412,14 & 8,76 & Rejeita H0 \\
\hline 5 & $\delta_{0}=0$ & 1814,51 & 183,14 & 2,71 & Rejeita H0 \\
\hline 6 & $\delta_{3}=0$ & 1864,17 & 83,82 & 2,71 & Rejeita H0 \\
\hline
\end{tabular}

* $\lambda$ : teste estatístico da razão de verossimilhança o qual apresenta uma distribuição aproximadamente quiquadrado com graus de liberdade iguais ao número de restrições independentes..

** Fonte: elaborada pelos autores. 
O terceiro teste verifica a estabilidade da fronteira de produção com relação à variável tempo, o que configura a presença ou não de progresso tecnológico. O resultado do teste rejeita a hipótese nula de que não houve progresso técnico.

A quarta hipótese nula refere-se ao teste de significância conjunta dos parâmetros usados na modelagem do componente ineficiência técnica. O resultado rejeita a hipótese de que os parâmetros são simultaneamente iguais a zero.

Os dois últimos testes verificam a significância de parâmetros específicos do modelo, relacionados à ausência de intercepto da ineficiência técnica, teste 5 , e da variável grau de abertura, teste 6 . Ambos rejeitam a hipótese nula de que deveriam ser desconsiderados.

\section{MEDIDAS DE PRODUTIVIDADE, RELAÇÃO CAPITAL-TRABALHO E DINÂMICA DISTRI- BUCIONAL}

Nessa seção, além das variações na $P T F M$ calculadas por 3 e de seus componentes de $V E T$ e de $V T$, calculadas, respectivamente, por 4 e 5 examina-se também o comportamento médio, em termos de taxas de variação, de outras medidas de produtividade que já são largamente utilizadas na literatura do crescimento. A intenção é a de comparar os resultados obtidos com as diversas medidas tentando retirar características comuns em suas evoluções. Acrescenta-se, ainda, a variação média da relação capital-trabalho em conjunto com as medidas de produtividade, a fim de possibilitar a identificação de efeitos de concentração ou dispersão e seus possíveis reflexos sobre o crescimento da produtividade.

\subsection{Variação média de produtividade e da relação capital-trabalho}

A construção das tabelas deste item obedeceu aos procedimentos convencionais de cálculo das variações médias das séries de dados, que estão explicitados no Apêndice 1.

Iniciando pela PTFM, observa-se na Tabela 3 que a OCDE apresentou o maior crescimento médio seguida pela Ásia e América Latina. A África teve um decréscimo de produtividade no período.

Vale destacar que, enquanto a Ásia teve em média um crescimento inferior ao observado para a OCDE, os países denominados de Tigres Asiáticos e de NICs, ${ }^{3}$ reconhecidos como centros dinâmicos da região asiática, apresentaram crescimento bem superior ao dos países ricos integrantes da OCDE.

Examinando-se os componentes resultantes da decomposição da PTFM, constata-se que a Ásia e a África sofreram regresso técnico, embora a primeira tenha tido um significativo crescimento médio da $V E T$ o que não aconteceu com a última.

É interessante observar que esse regresso técnico foi impulsionado pelos países dinâmicos da região, Tigres Asiáticos e os NICs, como informa a $V T$ média para o conjunto de países, se comparada com a dos integrantes desses grupos.

A América Latina apresentou $V T$ superior à da $\mathrm{OCDE}$, embora a forte variação negativa de eficiência tenha ocasionado um resultado final para a $P T F M$ que a colocou em terceiro lugar no desempenho geral. A OCDE foi o único grupo de países a apresentar um crescimento da $P T F M$ resultante da combinação tanto da $V E T$ como de $V T$.

Quanto ao produto per capita, e ao produto por trabalhador, a Ásia foi soberana, desbancado a OCDE que passou à segunda colocação. É realmente impressionante o crescimento médio observado dos Tigres Asiáticos e dos NICs, cuja taxa supera em muito aquela verificada para os demais blocos de países. A OCDE mantém assim mesmo um desempenho estável. Já a América Latina, se encontra novamente em terceiro lugar no que diz respeito ao produto per capita, mas perde posição para a África, ficando em quarto lugar, em relação ao produto por trabalhador. Quanto à África, a configuração conjunta dos indicadores de produtividade mostra que a região parece presa a um quadro de estagnação e pobreza.

${ }^{3}$ NICs é a abreviação na língua inglesa de New Industrialized Countries. 
Tabela 3 - Variação absoluta de produtividade e da relação capital-trabalho 1961-1990 - Variação Média (\%)

\begin{tabular}{lllllll}
\hline $\begin{array}{l}\text { Grupos de Países Re- } \\
\text { giões }\end{array}$ & $P T F M$ & $\begin{array}{l}\text { Variação } \\
\text { de Eficiên- } \\
\text { cia Técnica } \\
(V E T)\end{array}$ & $\begin{array}{l}\text { Variação } \\
\text { Tecno- } \\
\text { lógica } \\
(V T)\end{array}$ & $\begin{array}{l}\text { Produto } \\
\text { per Capita } \\
(\Delta P I B p c)\end{array}$ & $\begin{array}{l}\text { Produto } \\
\text { por Tra- } \\
\text { balhador } \\
(\Delta P I B p w)\end{array}$ & $\begin{array}{l}\text { Relação } \\
\text { Capital- } \\
\text { Trabalho } \\
\left(\frac{\Delta K}{L}\right)\end{array}$ \\
\hline AMÉRICA LATINA & 0,34 & $-0,33$ & 0,67 & 1,18 & 1,05 & 2,00 \\
OCDE & 0,59 & 0,11 & 0,47 & 2,93 & 2,57 & 3,44 \\
ÁSIA & 0,44 & 0,60 & $-0,15$ & 3,81 & 3,58 & 4,71 \\
- Tigres Asiáticos & 1,01 & 1,48 & $-0,47$ & 7,00 & 6,15 & 7,36 \\
- NICs & 0,82 & 1,00 & $-0,17$ & 5,83 & 5,22 & 6,91 \\
ÁFRICA & $-0,32$ & 0,15 & $-0,45$ & 1,21 & 1,35 & 1,80 \\
& & Amostra de Países - Estatísticas Descritivas & & \\
Média & 0,25 & 0,10 & 0,16 & 2,19 & 2,05 & 2,88 \\
Mediana & 0,41 & 0,09 & 0,32 & 2,20 & 2,01 & 2,75 \\
Desvio Padrão & 0,01 & 0,01 & 0,01 & 1,88 & 1,66 & 2,45 \\
Simetria & $-1,24$ & 0,87 & $-0,94$ & 0,55 & 0,54 & 0,35 \\
Curtose & 1,74 & 3,00 & 2,80 & 0,91 & 0,49 & 0,53 \\
\hline
\end{tabular}

Nota: São conhecidos como Tigres Asiáticos: Hong Kong, Coréia, Cingapura e Taiwan. Já os NICs (Países recém industrializados da Ásia) são integrados pelos Tigres Asiáticos e mais os seguintes países:Indonésia, Malásia e Tailândia. Fonte: elaborada pelos autores.

Às medidas de produtividade, acrescentou-se o exame do comportamento da relação capital-trabalho. Os dados são bastante reveladores do desempenho econômico dos países e mostram a importância do capital na dinâmica do crescimento. No caso da Ásia, observa-se uma combinação de desempenho bastante peculiar: regresso técnico e significativo crescimento da $V E T$, tendo como resultante uma variação positiva da $P T F M$ o que a coloca em segundo lugar na comparação com as demais, sendo superada apenas pela OCDE. Tudo isso combinado com uma realmente expressiva acumulação de capital.

Os resultados observados em termos do crescimento do produto per capita e do produto por trabalhador são os mais elevados na comparação geral. ${ }^{4}$ Um aspecto digno de registro é o que se refere ao desempenho dos Tigres Asiáticos e dos NICs quanto à acumulação de capital. Suas medidas da relação capital-trabalho alcançaram um crescimento médio mais do dobro da taxa verificada para a OCDE, cujo desempenho foi bastante significativo embora tenha sido superada também pela Ásia.

A América Latina apresenta uma variação na relação capital-trabalho muito próxima daquela observada para a África e representa aproximadamente $60 \%$ do crescimento médio da OCDE e apenas $42 \%$ daquele verificado na Ásia. Esse resultado leva a América Latina situar-se em terceiro lugar na avaliação geral com desempenho insignificante na acumulação do fator capital relativamente ao fator trabalho.

Uma pergunta que surge nesse ponto é se o crescimento médio verificado se deu de forma estável e sem inflexões. Os dados e resultados obtidos nas estimações mostram que existe um ponto no tempo, o ano de 1973, onde, a partir de então, algumas tendências nas medidas de produtividade se alteram. Pode-se explicar essa quebra, em parte, como decorrente do choque de oferta produzido pela crise de petróleo que eclodiu precisamente nesse ano. Para examinarem-se as alterações ocorridas, apresentamse as Tabelas 4 e 5, referentes aos períodos 1961-1973 e 1973-1990.

${ }^{4}$ Esse resultado constitui mais uma evidência de que o crescimento dos países do Leste da Ásia se deu devido à acentuada acumulação de capital e não a avanços na tecnologia como sugeriam alguns defensores dos modelos de crescimento endógeno, comprovando os argumentos de Krugman (1994) e Young (1994). 
Observando o comportamento das medidas de produtividade nas Tabelas 4 e 5 constata-se que, com exceção da OCDE quanto a $P T F M$, as taxas médias de crescimento sofrem quedas no período de 1973 a 1990 relativamente à fase anterior, mostrando-se significativas como no caso dos produtos per capita e por trabalhador da América Latina e África.

Manifesta-se, também, uma tendência de queda nas taxas de $V E T$, chegando alguns grupos de países a apresentar uma elevação na ineficiência técnica como acontece com a América Latina, OCDE e África. A Ásia, por sua vez, passa a enfrentar uma forte redução no ritmo de ganho de eficiência que havia se manifestado durante o período 1961-73. Por outro lado, América Latina e OCDE, embora convivendo com a redução na eficiência beneficiam-se de um forte impulso da $V T$ exatamente na fase de 1973-90.

Tabela 4 - Variação absoluta de produtividade e da relação capital-trabalho 1961-1973 - Variação Média (\%)

\begin{tabular}{lllllll}
\hline $\begin{array}{l}\text { Grupos de Países Re- } \\
\text { giões }\end{array}$ & PTFM & $\begin{array}{l}\text { Variação } \\
\text { de Eficiên- } \\
\text { cia Técnica } \\
(V E T)\end{array}$ & $\begin{array}{l}\text { Variação } \\
\text { Tecno- } \\
\text { lógica } \\
(V T)\end{array}$ & $\begin{array}{l}\text { Produto } \\
\text { per Capita } \\
(\Delta P I B p c)\end{array}$ & $\begin{array}{l}\text { Produto } \\
\text { por } \\
\text { balhador } \\
(\Delta P I B p w)\end{array}$ & $\begin{array}{l}\text { Relação } \\
\text { Capital- } \\
\text { Trabalho } \\
\left(\frac{\Delta K}{L}\right)\end{array}$ \\
\hline AMÉRICA LATINA & 0,36 & 0,78 & $-0,34$ & 2,53 & 2,72 & 5,09 \\
OCDE & 0,51 & 0,47 & 0,07 & 4,27 & 4,06 & 5,01 \\
ÁSIA & 0,89 & 1,30 & $-0,19$ & 4,26 & 4,23 & 7,42 \\
- Tigres Asiáticos & 2,36 & 3,36 & $-0,41$ & 8,38 & 7,67 & 6,53 \\
- NICs & 2,01 & 2,24 & $-0,06$ & 6,40 & 6,00 & 2,08 \\
ÁFRICA & $-0,29$ & 1,47 & $-1,31$ & 2,29 & 2,64 & 2,61 \\
& & Amostra de Países - Estatísticas Descritivas & & \\
Média & 0,33 & 0,97 & $-0,45$ & 3,30 & 3,37 & 3,61 \\
Mediana & 0,44 & 0,55 & $-0,27$ & 3,25 & 2,92 & 3,39 \\
Desvio Padrão & 1,03 & 1,49 & 1,58 & 2,21 & 2,09 & 2,63 \\
Simetria & $-0,30$ & 1,82 & $-1,34$ & 0,64 & 0,51 & 0,70 \\
Curtose & 1,41 & 3,78 & 2,99 & 1,19 & 0,46 & 0,83 \\
\hline
\end{tabular}

Fonte: elaborada pelos autores

Mais uma vez, chama a atenção o fato de que a Ásia, em particular os Tigres Asiáticos e os NICs, continua a manter uma forte taxa de acumulação de capital que se reflete por meio da variação média da relação capital-trabalho.

Mesmo os países ricos da OCDE, que tinham tido uma elevada taxa média de crescimento no primeiro subperíodo, sofrem uma queda na variação da relação capital-trabalho de mais da metade da variação observada de 1973 a 1990. A América Latina, que havia se beneficiado de uma elevada taxa de crescimento da relação capital-trabalho entre 1961 e 1990, passa a apresentar no segundo subperíodo uma queda na variação média da referida medida, levando-a a ocupar uma posição inferior à da África. Os dados apontam no sentido de que o crescimento da América Latina entre 1961 e 1973 decorreu da expansão do estoque de capital, uma vez que o desempenho da PTFM foi fortemente comprometido pelo regresso técnico da região.

\subsection{Níveis relativos de produtividade e da relação capital-trabalho}

As medidas de produtividade relativa e da relação capital-trabalho têm aplicação imediata na estimação das densidades Kernel. Elas permitem identificar a dinâmica de evolução das distribuições inerentes a estas medidas por meio da comparação do formato da distribuição em pontos distintos no tempo. 0 procedimento de construção das medidas, que está detalhado no Apêndice 2, é o seguinte: no caso da 
Tabela 5 - Variação de produtividade e da relação capital-trabalho 1973-1990 - Variação Média (\%)

\begin{tabular}{|c|c|c|c|c|c|c|}
\hline $\begin{array}{l}\text { Grupos de Países Re- } \\
\text { giões }\end{array}$ & $P T F M$ & $\begin{array}{l}\text { Variação } \\
\text { de Eficiên- } \\
\text { cia Técnica } \\
(V E T)\end{array}$ & $\begin{array}{l}\text { Variação } \\
\text { Tecno- } \\
\text { lógica } \\
(V T)\end{array}$ & $\begin{array}{l}\text { Produto } \\
\text { per Capita } \\
(P I B p c)\end{array}$ & $\begin{array}{l}\text { Produto } \\
\text { por Tra- } \\
\text { balhador } \\
(P I B p w)\end{array}$ & $\begin{array}{l}\text { Relação } \\
\text { Capital- } \\
\text { Trabalho } \\
\left(\frac{K}{L}\right)\end{array}$ \\
\hline AMÉRICA LATINA & 0,35 & $-0,95$ & 1,50 & 0,24 & $-0,10$ & 1,58 \\
\hline $\mathrm{OCDE}$ & 0,67 & $-0,05$ & 0,77 & 2,00 & 1,54 & 2,30 \\
\hline ÁSIA & 0,18 & 0,36 & $-0,08$ & 3,51 & 3,13 & 4,52 \\
\hline - Tigres Asiáticos & 0,08 & 0,70 & $-0,33$ & 6,04 & 5,09 & 7,32 \\
\hline - NICs & 0,03 & 0,57 & $-0,30$ & 5,44 & 4,68 & 7,19 \\
\hline ÁFRICA & $-0,32$ & $-0,46$ & 0,46 & 0,46 & 0,47 & 1,63 \\
\hline \multicolumn{7}{|c|}{ Amostra de Países - Estatísticas Descritivas } \\
\hline Média & 0,23 & $-0,30$ & 0,71 & 1,43 & 1,14 & 2,35 \\
\hline Mediana & 0,55 & $-0,18$ & 0,76 & 1,42 & 1,07 & 2,18 \\
\hline Desvio Padrão & 0,98 & 1,09 & 1,17 & 2,16 & 1,95 & 3,05 \\
\hline Simetria & $-1,13$ & $-0,22$ & 1,02 & 0,02 & 0,07 & 0,55 \\
\hline Curtose & 1,32 & 0,88 & 3,81 & 0,58 & 0,35 & 0,88 \\
\hline
\end{tabular}

Fonte: elaborada pelos autores.

PTFM e de seus componentes, tomando-se como referência o ano de 1970, multiplica-se a distância da fronteira de produção de cada país pelas suas respectivas taxas de crescimento anual até alcançar-se o ano desejado de comparação.

Em relação às outras medidas (produto per capita, produto por trabalhador e relação capital-trabalho), no ano inicial ou de referência ${ }^{5}$ usa-se a relação entre a medida de cada país e a correspondente medida dos Estados Unidos e, em seguida, acumula-se o resultado pelas taxas de crescimento relativas à variável de cada país até o ano escolhido. Os resultados apresentados na Tabela 6 referem-se a médias aritméticas dos países de cada região ou grupo.

Vale observar que a América Latina agora se situa em segundo lugar quanto ao nível da PTFM , e esse resultado pode ser explicado pelo fato da região encontrar-se próxima à fronteira em 1970. Isso também explicaria o maior nível de progresso técnico em relação à OCDE, só que, agora, pelo fato deste último grupo de países determinar a própria fronteira de produção. Deve-se lembrar que as medidas da PTFM são tomadas com referência à fronteira de produção no ano de 1970. Nas demais medidas, a OCDE é soberana em primeiro lugar e a Ásia em segundo com destaque para os Tigres Asiáticos e NICs.

\subsection{Produtividade total, capital-trabalho e dinâmica distribucional}

Apresentam-se nas Figuras de 1 a 6, a seguir, as densidades kernel estimadas das medidas discutidas na seção anterior. Por meio desse procedimento, pode-se analisar o comportamento dinâmico de suas distribuições permitindo assim compreender suas tendências de longo prazo. Além das densidades são apresentadas também as densidades normais teóricas para as mesmas medidas. As escalas dos gráficos são uniformes para cada figura.

Nas Figuras 1 e 2 o comportamento das densidades do produto per capita e do produto por trabalhador, relativas aos anos 1970, 1980 e 1990, revela uma evolução já bastante evidenciada na literatura sobre a distribuição dinâmica e crescimento (Quah, 1996a,b, 1997) acerca da tendência observada na economia mundial de estratificação ou formação de clubes de convergência.

${ }^{5}$ Adotou-se 1970 como o ano de referência para, em primeiro lugar, poder-se comparar os resultados com os obtidos em Krüger (2003), não obstante as diferenças metodológicas e amostrais utilizadas. Depois, porque se examina o comportamento das densidades Kernel nos anos iniciais das décadas de 1970, 1980 e 1990, permitindo comparações em períodos exatos de tempo. 
Tabela 6 - Níveis relativos de produtividade e da relação capital-trabalho 1961-1990

\begin{tabular}{|c|c|c|c|c|c|c|}
\hline $\begin{array}{l}\text { Grupos de Países Re- } \\
\text { giões }\end{array}$ & $P T F M$ & $\begin{array}{l}\text { Variação } \\
\text { de Eficiên- } \\
\text { cia Técnica } \\
(V E T)\end{array}$ & $\begin{array}{l}\text { Variação } \\
\text { Tecno- } \\
\text { lógica } \\
(V T)\end{array}$ & $\begin{array}{l}\text { Produto } \\
\text { per Capita } \\
(P I B p c)\end{array}$ & $\begin{array}{l}\text { Produto } \\
\text { por Tra- } \\
\text { balhador } \\
(P I B p w)\end{array}$ & $\begin{array}{l}\text { Relação } \\
\text { Capital- } \\
\text { Trabalho } \\
\left(\frac{K}{L}\right)\end{array}$ \\
\hline AMÉRICA LATINA & 1,02 & 0,80 & 1,25 & 0,30 & 0,37 & 0,26 \\
\hline $\mathrm{OCDE}$ & 1,09 & 0,94 & 1,10 & 1,13 & 1,03 & 1,05 \\
\hline ÁSIA & 0,93 & 0,93 & 0,89 & 0,40 & 0,37 & 0,25 \\
\hline - Tigres Asiáticos & 0,91 & 0,97 & 0,83 & 0,91 & 0,77 & 0,54 \\
\hline$-\mathrm{NICs}$ & 0,91 & 0,89 & 0,85 & 0,65 & 0,59 & 0,40 \\
\hline ÁFRICA & 0,83 & 0,80 & 0,93 & 0,13 & 0,10 & 0,05 \\
\hline \multicolumn{7}{|c|}{ Amostra de Países - Estatísticas Descritivas } \\
\hline Média & 0,97 & 0,86 & 1,05 & 0,52 & 0,49 & 0,44 \\
\hline Mediana & 0,99 & 0,91 & 1,04 & 0,30 & 0,37 & 0,25 \\
\hline Desvio Padrão & 0,18 & 0,13 & 0,29 & 0,48 & 0,41 & 0,46 \\
\hline Simetria & $-0,31$ & $-1,16$ & 1,61 & 0,82 & 0,64 & 0,95 \\
\hline Curtose & $-0,02$ & 0,41 & 9,17 & $-0,84$ & $-1,03$ & $-0,53$ \\
\hline
\end{tabular}

Fonte: elaborada pelos autores.

Figura 1 - Densidades do Produto per capita Normalizado
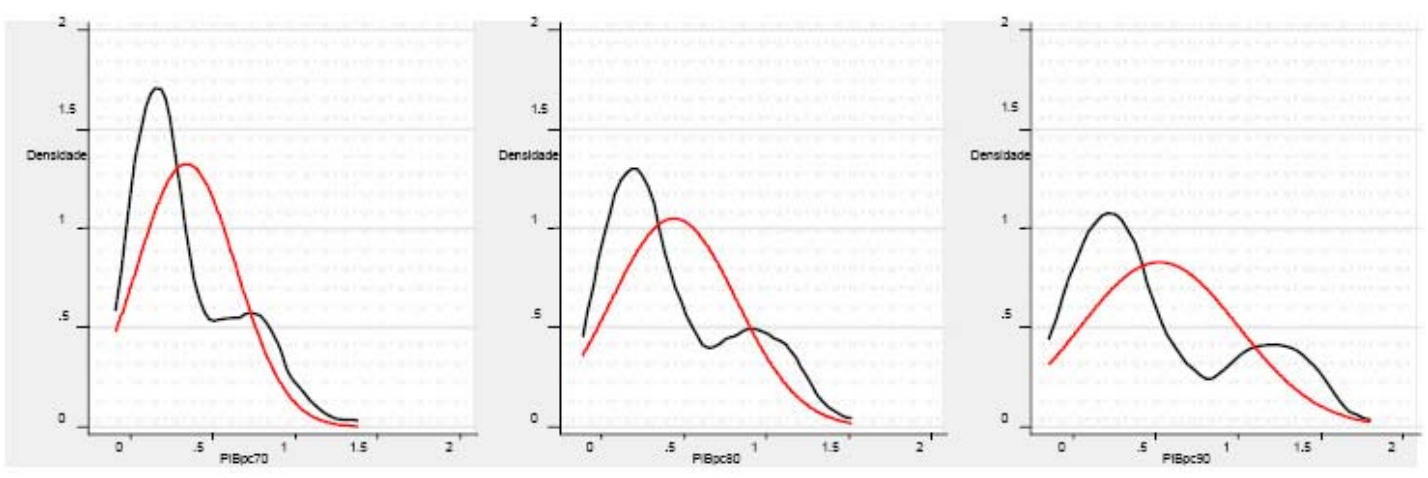

Figura 2 - Densidades do Produto por Trabalhador Normalizado
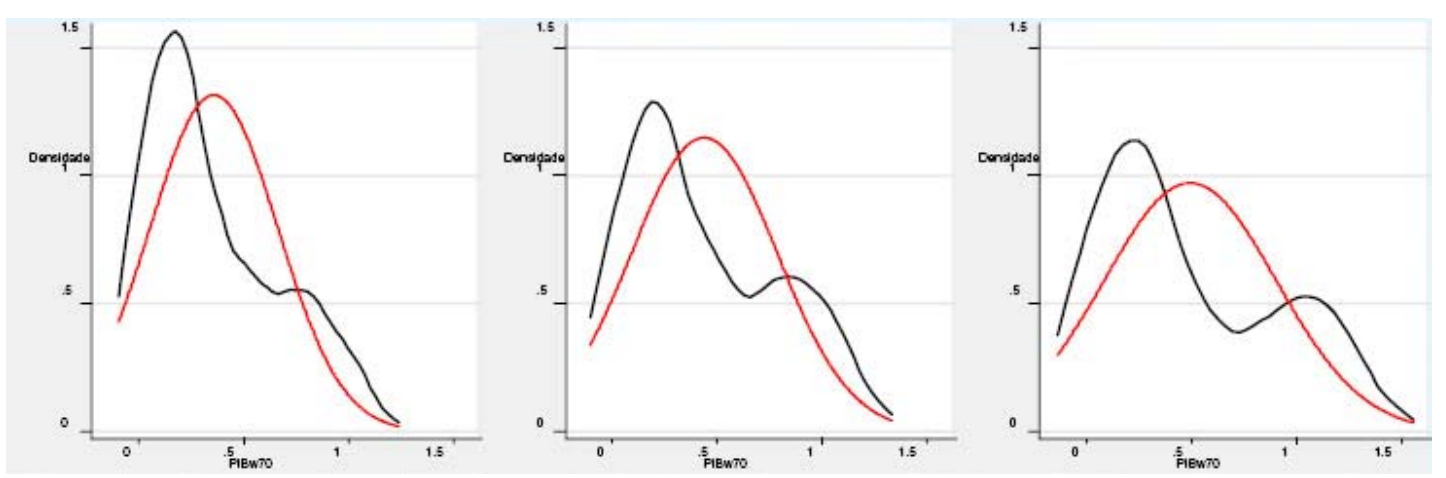

RBE Rio de Janeiro $\quad$ v. 60 n. 3/p. 261-279 Jul-Set 2006 
Há claramente formação de bimodalidade e o capital por trabalhador e capital-trabalho modal tendem a aumentar ao longo do tempo. Observa-se, também, um aumento da dispersão de ambas densidades em torno de suas duas modas.

Nos dois casos examinados, observa-se um movimento de massa de probabilidade para a direita da distribuição, consolidadndo uma evidente conformação de bimodalidade e uma provável consolidação no tempo dessa tendência.

Um aspecto interessante e novo nessa abordagem refere-se à comparação da dinâmica da densidades do produto por trabalho (Figura 2) com os movimentos da densidade da relação capital-trabalho normalizada (Figura 3). É nítida a semelhança nas dinâmicas de ambas distribuições.

Figura 3 - Densidades da Relação Capital-Trabalho Normalizada
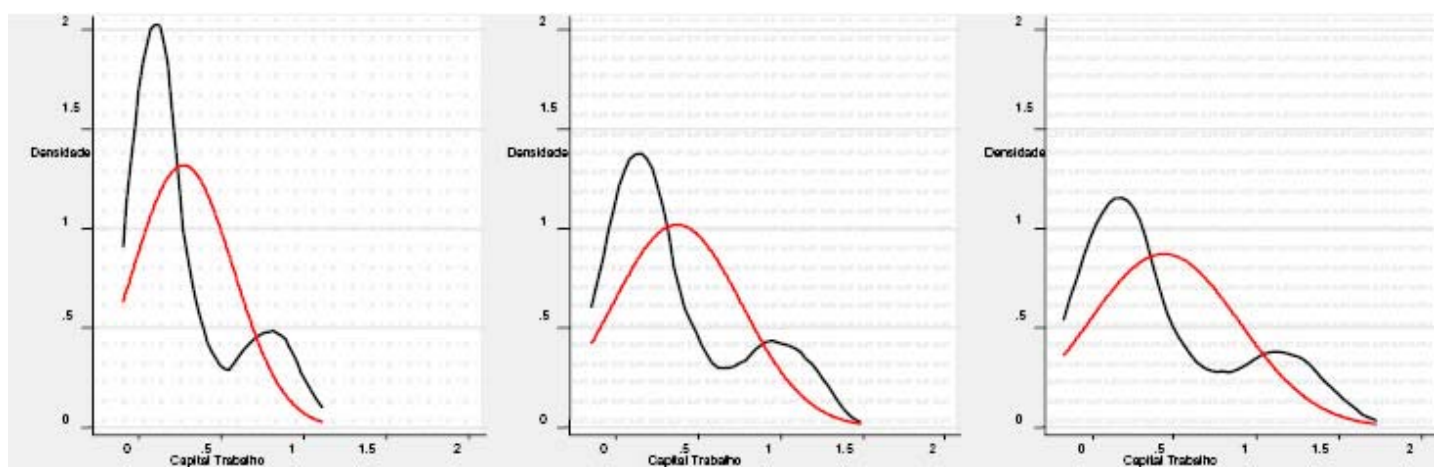

A dinâmica da relação capital-trabalho sugere que a acumulação de capital físico constitui o fator chave na explicação das grandes diferenças nos níveis de renda per capita dos países e que, conforme Lucas (1990), esse fator de produção não flui dos países ricos para os pobres como o modelo neoclássico de crescimento sugere.

Figura 4 - Densidades da Produtividade Total dos Fatores Normalizada
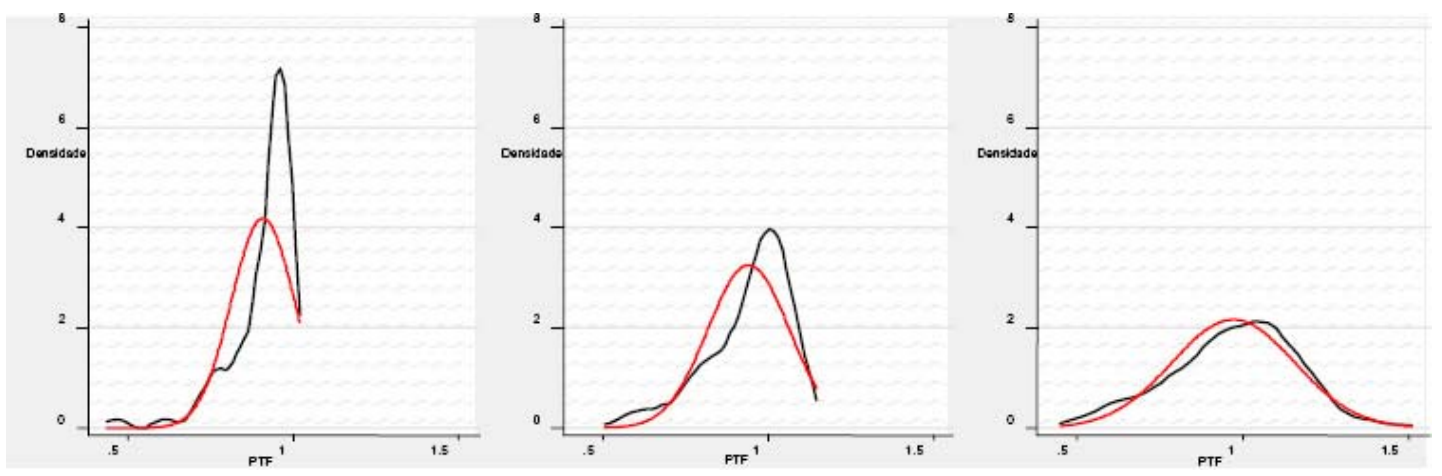

O comportamento da $P T F M$, Figura 4, é influenciado pela forma de decomposição do índice de produtividade total de Malmqüist. De acordo com a Figura 5, o aumento da dispersão da $V E T$ e o deslocamento de massa de probabilidade para a direita, faz com que a PTFM também apresente as mesmas características. Observa-se que na, Figura 6, a $V T$ também apresenta aumento na sua dispersão e deslocamento de sua moda para a direita mas, no entanto, com menos intensidade. 
Figura 5 - Densidades da Variação de Eficiência Técnica Normalizada
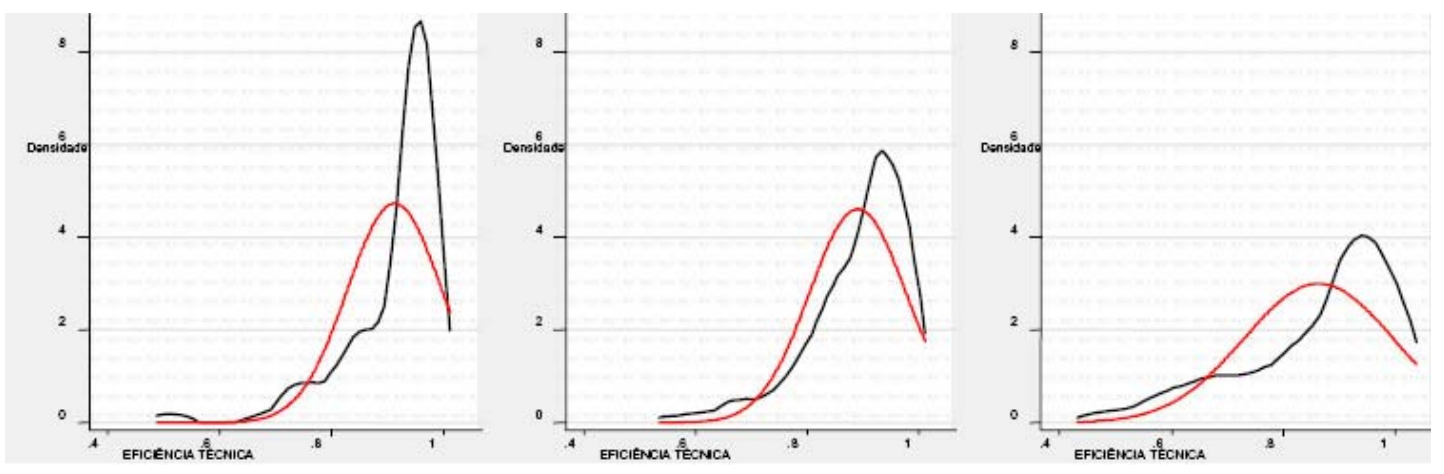

Figura 6 - Densidades da Variação Tecnológica Normalizada

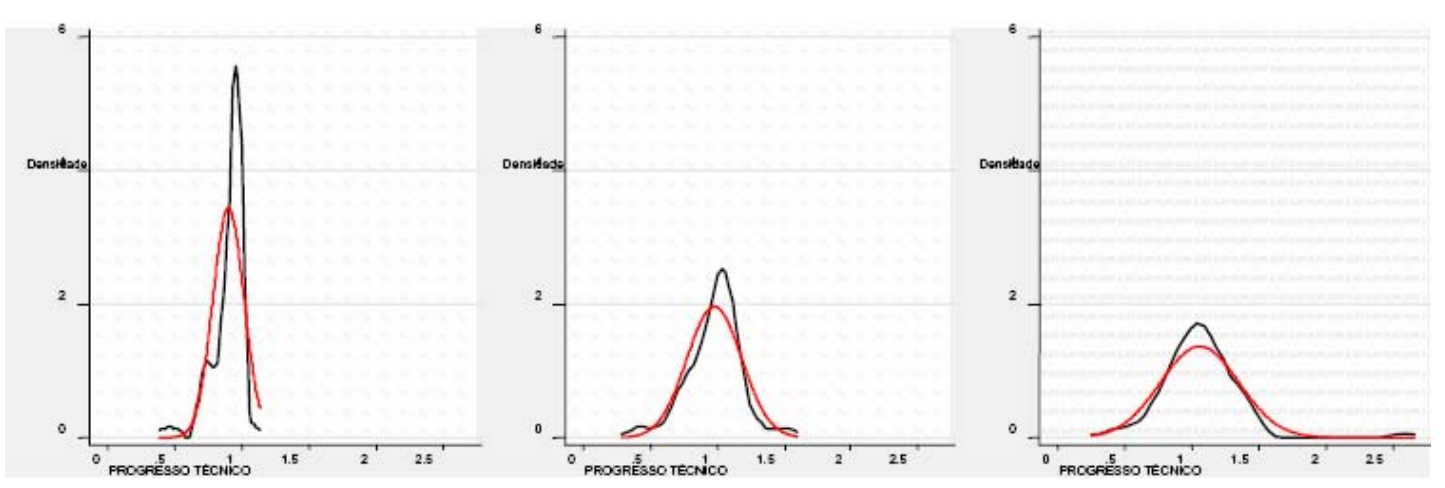

O resultado é uma densidade de probabilidade muito próxima da normal com sutis diferenças: ocorre um achatamento na moda da distribuição e uma leve tendência à formação de uma segunda moda no seu segmento inferior. Há, portanto, uma variedade de taxas de crescimento da $P T F M$, o que permitiria explicar a grande diversidade observada nas taxas de crescimento econômico dos países e cuja tendência de aumento da dispersão se manifesta ao longo do tempo.

Um exame no interior das distribuições permite informações mais detalhadas sobre aspectos de sua dinâmica, notadamente em relação às alterações muito acentuadas de posições e à consolidação de tendências. Assim, com o propósito de se realizar essa verificação, realizou-se o agrupamento dos países relativos a cada uma das distribuições em quartis. No caso específico do produto per capita, constatase que do total de 75 países da amostra 23 mudaram de quartil entre 1970 e 1990 . Em nenhuma situação ocorreu uma alteração de posição que pudesse ser caracterizada como um grande avanço ou um grave retrocesso. As modificações observadas ocorrem, em geral, de um quartil para outro vizinho e as alterações mais relevantes são mencionadas a seguir. Dois países, Argentina e Venezuela, chamam a atenção pelo recuo em suas posições. Em 1970 ambos integravam o último quartil e, em 1990, caem para o terceiro quartil. Aliás, essa situação se repete com os dois nas outras medidas. República Centro Africana, Honduras e Costa do Marfim passam do segundo quartil para o primeiro. Hong Kong e Cingapura sobem do terceiro para o quartil superior, sendo que no caso do primeiro país essa posição já é alcançada em 1980. O Brasil permanece sempre no terceiro quartil, embora com dinâmica descendente 
em relação à sua posição ocupada naquele estrato.

\section{CONCLUSÕES FINAIS}

Na abordagem aqui adotada, a PTFM foi decomposta em $V E T$ e $V T$, permitindo assim a identificação destes componentes sobre o crescimento da produtividade total dos fatores. A preocupação principal residia na comparação dos desempenhos de grupos ou regiões de países e, para isso, utilizouse de outras medidas de produtividade e também da relação capital-trabalho.

Em relação aos efeitos das variáveis macroeconômicas na explicação da componente de ineficiência técnica, constatou-se que os gastos correntes do governo e o grau de abertura constituíram fatores significantes para o aumento da ineficiência técnica dos países. Este último resultado surpreendeu devido à existência de trabalhos empíricos demonstrando os benefícios da abertura econômica como fator impulsionador da eficiência técnica. Mas a amostra aqui considerada é bastante heterogênea e incorpora, por exemplo, países da África que apresentam medidas de abertura bastante elevadas, mas que, ao mesmo tempo, distinguem-se pelo grau de ineficiência macroeconômica. Pode ser uma explicação para este resultado e, talvez, fosse mais recomendado analisar esse efeito considerando grupos de países mais homogêneos.

Já o os desvios dos preços locais em relação à paridade do poder de compra, revelaram-se importantes fatores indicativos para a redução da ineficiência técnica.

Quanto a PTFM, observou-se um persistente padrão de manutenção das diferenças de crescimento entre os países e nenhuma alteração no quadro de liderança do grupo de países integrantes da OCDE, seguido pela Ásia. A América Latina apresentou um resultado positivo no crescimento da PTF $M$, mas manteve sempre a terceira colocação entre os grupos de países analisados. A forte perda de $V E T$ teve considerável peso no resultado final da $P T F M$, mais que compensando os ganhos de $V T$. Já a Ásia, apresentou regresso tecnológico, mas um forte ritmo médio de expansão de $V E T$, que resultou em crescimento de sua PTFM. A África teve desempenho insuficiente para resgatá-la da última colocação e parece presa a uma armadilha da pobreza.

Examinou-se também o comportamento da PTFM, e de seus componentes, em dois sub-períodos: de 1961 a 1973 e de 1973 a 1990. Os dados relativos ao intervalo 1973 a 1990 indicam que efetivamente ocorreu uma inflexão nos padrões de crescimento da produtividade em relação ao primeiro sub-período, sendo que a provável causa para isso pode estar relacionada ao choque de oferta causado pela crise do petróleo de 1973. Observa-se a ocorrência de uma queda generalizada de $V E T$ dos países, chegando a atingir até mesmo os integrantes da OCDE. A América Latina também passa a enfrentar fortes quedas de eficiência nessa fase. Não obstante a esse fato, é nesse segundo subperíodo que se constata um crescente avanço tecnológico tanto da OCDE quanto da própria América Latina, que havia amargado um quadro de regresso técnico na fase anterior.

Um aspecto importante está relacionado ao crescimento da relação capital-trabalho e suas conexões com o avanço tecnológico e com o crescimento econômico. O elevado crescimento dos países da Ásia, mais especificamente daqueles conhecidos como Tigres Asiáticos e NICs, teve forte suporte na acumulação de capital físico. Mesmo apresentando quadro de regresso técnico, as produtividades do trabalho mantiveram ritmos de crescimento acima dos padrões médios, tendo sido impulsionadas pelas taxas de acumulação de capital. Os dados relativos à OCDE mostram também uma forte tendência de acumulação de capital. 0 exame dos desempenhos dos países no segundo subperíodo mostra que mesmo com as quedas observadas nos ritmos da PTFM, o crescimento da produtividade do trabalho nos países da OCDE e da Ásia teve como explicação o processo de acumulação de capital.

Uma forte evidência da importância do capital físico na explicação da dinâmica econômica é identificada no exame do comportamento da relação capital-trabalho relativa, a qual apresenta um padrão evolutivo semelhante tanto ao do produto per capita quanto ao do produto por trabalhador. 0 exame da dinâmica distribucional revela, ainda, a tendência à bipolarização do padrão de desenvolvimento e a 
formação de clubes de convergência, sugerindo a conclusão de que o capital físico determina o padrão de renda dos países e que a produtividade total dos fatores explica as grandes diferenças nas suas taxas de crescimento.

\section{Referências Bibliográficas}

(2002). Economic Growth Research. The World Bank Group. http: //www . worldbank . org/research/ growth/GNDdata.htm. Acesso em 12 out 2002.

Battese, G. E. \& Coelli, T. J. (1993). A stochastic frontier production incorporating a model for technical inneficiency effects. Technical Report 69, University of New England, Department of Econometrics.

Battese, G. E. \& Coelli, T. J. (1995). A model for technical inefficiency effects in a stochastic frontier production function for panel data. Empirical Economics, 20(2):325-32.

Caves, D. W., Christensen, L. R., \& Diewert, W. E. (1982). Multilateral comparisons of output, input and productivity using superlative index numbers. Economic Journal, 92(365):73-86.

Fare, R., Grosskopf, S., Norris, M., \& Zhang, Z. (1994). Productivity growth, technical progress, and efficiency change in industrialized countries. American Economic Review, 84(1):66-83.

Farrell, M. J. (1957). The measurement of productive efficency. Journal of the Royal Statistical Society, Series A 170:253-290.

Heston, A., Summers, R., \& Aten, B. (2002). Penn world table version 6.1. Technical report, Center for International Comparisons at the University of Pennsylvania (CICUP).

Kodde, D. A. \& Palm, F. C. (1986). Wald criteria for jointly testing equality and inequality restriction s. Econometrica, 54(5):1243-48. available at http://ideas.repec.org/a/ecm/emetrp/ v54y1986i5p1243-48.html.

Krugman, P. R. (1994). The myth of asia’s miracle. Foreign Affairs, 73:62-78.

Krüger, J. J. (2003). The global trends of total productivity: evidence from nonparametric malmquist index approach. Oxford Economics Papers, 55:265-286.

Lucas, Robert E, J. (1988). On the mechanics of economic development. Journal of Monetary Economics, 22:3-42.

Lucas, Robert E, J. (1990). Why doesn't capital flow from rich to poor countries? American Economic Review, 80(2):92-96.

Malmqüist, S. (1953). Index number and indiference curves. Trabajos de Estadística, 4(1):209-42.

Mankiw, N. G., Romer, D., \& Weil, D. N. (1992). A contribution to the empirics of economic growth. The Quarterly Journal of Economics, 107(2):407-37. available at http://ideas.repec . org/a/tpr/ qjecon/v107y1992i2p407-37.html.

Marinho, E. L. L. \& Silva, A. B. (2003). Produtividade e crescimento econômico da américa latina: A abordagem de fronteira estocástica de produção. In VII Encontro Regional de Economia - ANPEC Anais do VII Encontro Regional de Economia, Fortaleza, CE.

Nuxoll, D. A. (1994). Differences in relative prices and international differences in growth rates. American Economic Review, 84(5):1423-36. available at http://ideas.repec.org/a/aea/aecrev/ v84y1994i5p1423-36.html. 
Quah, D. T. (1996a). Convergence as distribution dynamics (with or without growth). Technical report, LSE Discussion Paper.

Quah, D. T. (1996b). Twin peaks: Growth and convergence in models of distribution dynamics. Economic Journal, 106(437):1045-55. available at http://ideas.repec.org/a/ecj/econjl/ v106y1996i437p1045-55.html.

Quah, D. T. (1997). Empirics for growth and distribution: Stratification, polarization and convergence clubs. Journal of Economic Growth, 2(1):27-59. available at http://ideas.repec.org/a/kap/ jecgro/v2y1997i1p27-59.html.

Romer, P. (1986). Increasing returns and long-run growth. Journal of Political Economy, 94:1002-1037.

Silverman, B. W. (1998). Density estimation for statistics and data analysis. Number 26 in Monographs on Statistics and Applied Probability. Chapman and Hall/CRC, New York.

Solow, R. M. A. (1956). Contribuition to the theory of economic growth. Quarterly Journal of Economics, 70(1):65-94.

Young, A. (1994). The tyranny of numbers: Confronting the statistical realities of the east asian growth experience. NBER Working Paper, 4680:1-39.

\section{A. CÁLCULO DAS VARIAÇÕES MÉDIAS DAS SÉRIES DE DADOS}

$$
\begin{aligned}
& \Delta P T F M_{h}=\left(\left[\prod_{t=t_{1}}^{t_{2}} \operatorname{PTFM}\right]^{\frac{1}{\left(t_{2}-t_{1}\right)}}-1\right) .100 \\
& \Delta V T_{h}=\left(\left[\prod_{t=t_{1}}^{t_{2}} V T\right]^{\frac{1}{\left(t_{2}-t_{1}\right)}}-1\right) .100 \\
& \Delta V E T_{h}=\left(\left[\prod_{t=t_{1}}^{t_{2}} V E T\right]^{\frac{1}{\left(t_{2}-t_{1}\right)}}-1\right) .100 \\
& \Delta P I B_{p c_{h}}=\left(\left[\prod_{t=t_{1}}^{t_{2}} \frac{R G D P C H_{h}^{t_{2}}}{R G P C H_{h}^{t_{1}}}\right]^{\frac{1}{\left(t_{2}-t_{1}\right)}}-1\right) .100 \\
& \Delta P I B_{p t_{h}}=\left(\left[\prod_{t=t_{1}}^{t_{2}} \frac{R G D P W_{h}^{t_{2}}}{R G P W_{h}^{t_{1}}}\right]^{\frac{1}{\left(t_{2}-t_{1}\right)}}-1\right) .100 \\
& \Delta(K / L)_{p t_{h}}=\left(\left[\prod_{t=t_{1}}^{t_{2}} \frac{(K / L)_{h}^{t_{2}}}{(K / L)_{h}^{t_{1}}}\right]^{\frac{1}{\left(t_{2}-t_{1}\right)}}-1\right) .100
\end{aligned}
$$




\section{rbe}

\section{B. CONSTRUÇÃO DAS MEDIDAS}

$$
\begin{aligned}
P T F M_{h} & =D_{0 h}^{1970}\left(x_{h}^{1970}, y_{h}^{1970}\right) \cdot \prod_{t=1971}^{1990} P T F M_{h}^{t} \\
P I B_{p c_{h}} & =\frac{P I B_{p c_{h}}^{1970}}{P I B_{p c_{E U A}}^{1970}} \prod_{t=1971}^{1990} \frac{P I B_{p c_{h}}^{t}}{P I B_{p c_{h}}^{t-1}} \\
P I B_{w_{h}} & =\frac{P I B_{w_{h}}^{1970}}{P I B_{w_{E U A}}^{1970}} \prod_{t=1971}^{1990} \frac{P I B_{w_{h}}^{t}}{P I B_{w_{h}}^{t-1}} \\
(K / L)_{h} & =\frac{(K / L)_{h}^{1970}}{(K / L)_{E U A}^{1970}} \prod_{t=1971}^{1990} \frac{(K / L)_{h}^{t}}{(K / L)_{h}^{t-1}}
\end{aligned}
$$

onde $h=1,2, \ldots, 75$;

PTF $M$ - Produtividade total de Malmquist; $V E T$ - variação de eficiência técnica; $V T$ - variação tecnológica; $P I B p c$ - produto interno bruto per capita; $P I B w$ - produto interno bruto por trabalhador; $(K \mid L)$ - relação capital-trabalho; - é a medida da distância da fronteira de produção de cada país em 1970, definida na seção 2.2 . 